\title{
Studi Partisipasi Masyarakat dan Pemerintah dalam Mengurangi Resiko Bencana Abrasi di Wilayah Pesisir Pantai Nggelu Kabupaten Bima
}

\author{
${ }^{1}$ Fifiarna, ${ }^{2}$ Sukuryadi, ${ }^{3}$ Nurin Rochayati \\ ${ }^{1}$ Pendidikan Geografi, Universitas Muhammadiyah Mataram, Indonesia \\ fiarna@gmail.com, sukuryadi@gmail.com, nurin.geo99@gmail.com,
}

\begin{abstract}
ARTICLE INFO
Article History:

Received : 12-09-2018

Revised : 17-11-2018

Accepted : 21-11-2018

Online : 30-11-2018

Keywords:

Partisipasi Masyarakat;

Bencana Abrasi; Wilayah Pesisir
\end{abstract}

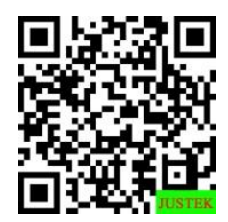

\begin{abstract}
Abstract: Community participation to reduce and avoid the risk of disasters is important by increasing public awareness and capacity. This study aims to describe the participation of communities and governments on the coast in reducing the risk of disaster in Lambu District, Bima Regency. The method used in this research is qualitative research method. The method of determining informants, the way of determining informants in this study is by purposive sampling. Data collection method is done through observation, interview and documentation. Data analysis used is data reduction, data presentation and data verification. The result of the research, namely (a) mangrove tree planting and greening around the beach is one of the efforts of the Local Government in NTB, especially in Nggelu Village (b) legal counseling to the people of Nggelu Village, providing knowledge to local fishermen about the legislation related to marine and fishery. The advice in the research is that the coastal communities of Nggelu Village to better maintain the coastal environment by not littering and maintaining the sustainability of mangrove forests and not cutting them down.
\end{abstract}

\begin{abstract}
Abstrak: Partisipasi masyarakat untuk mengurangi dan menghindari resiko bencana penting dilakukan dengan cara meningkatkan kesadaran dan kapasitas masyarakat. Penelitian ini bertujuan untuk mendeskripsikan partisipasi masyarakat dan pemerintah di pesisir dalam mengurangi resiko bencana di Kecamatan Lambu Kabupaten Bima. Metode yang digunakan dalam penelitian ini adalah metode penelitian kualitatif. Metode penentuan informan, cara penentuan informan dalam penelitian ini adalah dengan purposive sampling. Metode pengumpulan data dilakukan melalui observasi, wawancara dan dokumentasi. Analisis data yang digunakan yaitu reduksi data, penyajian data dan verifikasi data. Hasil penelitian yaitu (a) penanaman pohon mangrove dan penghijauan di sekitar pantai merupakan salah satu upaya Pemerintah Daerah di NTB khususnya yang terjadi di Desa Nggelu (b) penyuluhan hukum terhadap masyarakat Desa Nggelu, memberikan pengetahuan terhadap para nelayan setempat tentang peraturan perundang-undagan yang berkaitan dengan kelautan dan perikanan. Adapun saran dalam penelitian yaitu masyarakat wilayah pesisir pantai Desa Nggelu agar lebih menjaga lingkungan pesisir dengan tidak membuang sampah sembarangan dan menjaga kelestarian hutan bakau (mangrove) degan tidak menebangnya.
\end{abstract}




\section{A. LATAR BELAKANG}

Pantai dan pesisir merupakan istilah dalam dunia kelautan yang sering kali terdengar bergandengan, hal ini dikarenakan oleh keterkaitan antara pantai dan pesisir yang sangat erat (Herianto et al. 2020)(N. Rochayati et al. 2020). Pantai merupakan sebab pertama lahirnya istilah pesisir dan sebaliknya pesisir sangat memberi pengaruh terhadap dinamika pantai (N. Rochayati et al. 2020)(Haryawan and Sukuryadi 2019)(Herianto et al. 2020). Setiap kejadian bencana yang terjadi di Kecamatan Lambu menimbulkan dampak bagi masyarakat yang pemukiman dilingkungan yang terkena dampak langsung oleh bencana, yang mengakibatkan mata pencaharian dan aktifitas terhenti terutama yang untuk nelayan (Sukuryadi 2018)(N. Rochayati et al. 2020). Sebelum tahun 2013 garis pantai yang ada di Lingkungan Desa Nggelu masih bisa sebagai tempat bersandarnya perahu nelayan, namun akibat abrasi lingkungan ini kini menjadi daerah yang sangat rentan terhadap air pasang (Sukuryadi and Ali 2018)(Herianto et al. 2020). Hal ini diparahkan juga dengan tidak adanya pohon pelindung pantai yang dapat menahan hempasan ombak pantai (Sukuryadi et al. 2020)(Herianto et al. 2020). Sehingga pada tahun 2014 juga akan mengalami dampak yang tidak jauh berbeda keadaan di tahun 2012 (N. Rochayati et al. 2020)(Herianto et al. 2020)

Provinsi Nusa Tenggara Barat merupakan daerah yang memiliki wilayah pantai yang banyak, sehingga menjadikan wilayah Nusa Tenggara Barat menjadi sangat rentah dan rawan terhadap ancaman bencana abrasi pantai maupun kerusakan bangunan pantai (Nurin Rochayati, Pramunarti, and Herianto 2018). Abrasi yaitu sebuah proses berkurangnya daratan yang disebabkan oleh gelombang laut. Abrasi juga sering disebut erosi laut pengikisan pantai secara alamiah (Mulyadi, Asep dkk, 2008: 28)(Herianto et al. 2020). Tetapi dengan terganggunya keseimbangan misalnya berkurangnya hutan bakau dan terumbu karang (N. Rochayati et al. 2020)(Herianto et al. 2020). Pengikisan menjadi tidak terkendali dan tidak jarang proses abrasi menjadi bencana (Herianto et al. 2020)(Faisal, Sukuryadi, and Wulandari 2018). Bencana alam disuatu wilayah memiliki implikasi secara langsung terhadap masyarakat di wilayah tersebut (Nurin Rochayati, Pramunarti, and Herianto 2018). Partisipasi masyarakat untuk mengurangi dan menghindari resiko bencana penting dilakukan dengan cara meningkatkan kesadaran dan kapasitas masyarakat (Nurin Rochayati et al. 2018)(Herianto et al. 2020). Karena masyarakat merupakan pihak yang memiliki pengalaman langsung dalam kejadian bencana sehingga pemahaman yang dimiliki menjadi modal bagi pengurangan resiko bencana (Faperi and Hendrarto 2015)(Haryawan and Sukuryadi 2019).

Dengan melihat dari letak Kabupaten Bima yang sangat dekat dengan pesisir pantai menjadikan Kabupaten Bima sangat rentah terhadap bencana abrasi (Adhian, Suprapto, and Purwanti 2014)(Herianto et al. 2020). Dengan demikian inisiasi program penanggulangan bencana menjadi penting dan memiliki nilai strategi untuk terus didorong oleh pemerintah (Koddeng 2011)(Sutrisno, Irwan, and Ramli 2019)(Herianto et al. 2020). Hal ini merupakan respon yang harus diambil pemerintah Kabupaten Bima untuk menghindari timbulnya korban jiwa manusia, kerusakan lingkungan, kerugian harta benda, dan dampak psikologis yang lebih besar lagi (Handayani 2019)(N. Rochayati et al. 2020). Terutama untuk daerah yang berbatasan langsung dengan bibir pantai seperti lingkungan Desa Nggelu Kecamatan Lambu. Penelitian ini terfokus pada partisipasi pemerintah dan masyarakat dalam mengurangi resiko bencana abrasi di wilayah pesisir lingkungan Desa Nggelu Kecamatan Lambu Kabupaten Bima. Untuk mengetahui tentang pengurangan resiko Bencana Abrasi yang terdapat pada daerah Wilayah pesisir Desa Nggelu Kecamatan Lambu. 
Tujuan penelitian ini adalah untuk mendeskripsikan partisipasi masyarakat dan pemerintah di pesisir dalam mengurangi resiko bencana di Kecamatan Lambu Kabupaten Bima.

\section{B. METODE PENELITIAN}

Jenis penelitian yang digunakan adalah penelitian kualitatif. Dalam penelitian kualitatif, pengumpulan data tidak dipandu oleh teori, tetapi dipandu oleh fakta-fakta yang ditemukan pada saat penelitian dilapangan (Sugiyono 2013)(Arikunto 2010). Penelitian ini dilaksanakan di Lingkungan Desa Nggelu Kecamatan Lambu Kabupaten Bima. Subjek penelitian yang digunakan adalah responden. Sumber data dalam penelitian ini adalah informasi dan benda serta situasi lingkungan secara keseluruhan dari mana data-data yang relavan untuk terjawabnya masalah penelitian ini. Metode pengumpulan data dalam penelitian menggunakan observasi, wawancara dan dokumentasi. Analisis Data yang digunakan dalam penelitian ini dengan reduksi data, penyajian data dan penarikan kesimpulan

\section{HASIL DAN PEMBAHASAN}

Partisipsi masyarakat dan pemerintah dalam mengatasi bencana abrasi di Desa Nggelu Kecamatan Lambu Kabupaten Bima. Wilayah pesisir pantai memiliki potensi yang tak ternilai bagi masyarakat. Perairan pantai tidak saja menjadi sumber pangan yang produktif, tetapi juga sebagai gudang mineral, alur pelayaran, tempat rekreasi dan juga sebagai tangki pencerna bahan buangan hasil kegiatan manusia. Besarnya sumber alam yang terkandung di dalamnya, hayati maupun non hayati serta aneka kegunaan yang bersifat ganda merupakan bukti yang tidak dapat disangkal, bahkan menjadi tumpuan harapan manusia dalam usahanya memenuhi kebutuhan pangan yang terus meningkat di masa mendatang. Upaya penanggulangan abrasi yang telah dilakukan Pemerintah Daerah setempat adalah membangun groin di sepanjang garis pantai Desa Nggelu dengan panjang $30 \mathrm{~m}$ dan jarak antar groin sekitar $50 \mathrm{~m}$. Cara penanganan tersebut perlu dievaluasi secara cermat, mengingat proses abrasi terus berkembang ke arah utara pesisir Desa Nggelu. Upaya penanggulangan abrasi secara alamiah perlu juga dilakukan seperti penanaman pohon kelapa dan, pohon mangrove di sekitar pantai untuk mengurangi dampak abrasi yang lebih besar.

Berdasarkan hasil observasi yang telah dilakukan keadaan wilayah pesisir Desa Nggelu cukup memprihatinkan karena adanya peningkatan kegiatan yang mengkonversi hutan mangrove menjadi peruntukan lain yaitu pembukaan lahan tambak ikan dan udang, selain itu juga dikarenakan adanya eksploitasi (penebangan) tumbuhan mangrove untuk dijadikan kayu bakar oleh masyarakat sekitar Desa Nggelu. Perubahan kawasan mangrove menjadi lahan tambak ikan dan udang oleh masyarakat Desa Nggelu sebenarnya bukan karena tidak ada alasan, hal ini disebabkan karena hasil tangkapan ikan di laut sudah sangat berkurang sehingga biaya yang mereka keluarkan untuk pergi melaut terkadang lebih besar dari pada hasil tangkapan. Selain kawasan hutan mangrove yang rusak akibat beralih fungsi menjadi lahan tambak ikan dan udang, wilayah pesisir pantai Desa Nggelu juga terkena pencemaran lingkungan. Hal ini terlihat dari banyaknya sampah yang menggenang baik yang berada di kawasan pemukiman penduduk dan sekitar wilayah pesisir Desa Nggelu. Bukan itu saja sampah-sampah sisa aktivitas ekonomi, sampah rumah tangga dan tumpahan bahan bakar minyak dari kapal-kapal yang berlabuh di wilayah pesisir Desa Nggelu.

Upaya-upaya yang dilakukan oleh pemerintah daerah yaitu (1) Penanaman pohon mangrove merupakan salah satu upaya Pemerintah Daerah (Pemda) di NTB khususnya yang terjadi di Desa Nggelu, dirangkaikan dengan penanaman pohon penghijauan di 
sekitar pantai; (2) Penyuluhan hukum terhadap masyarakat Desa Nggelu, di maksudkan untuk memeberikan pengetahuan terhadap para nelayan setempat tentang peraturan perundang-undagan yang berkaitan dengan kelautan dan perikanan; (3) Memberikan bantuan berupa buku bacaaan untuk masjid yang ada di desa tersebut. Buku-buku bacaan yang diberikan bertujuan agar masyarakat pesisir gemar membaca.

Peran Pemerintah Desa Nggelu dalam pelestarian lingkungan pesisr pantai yaitu :

1. Pembuatan Tanggul Pesisir

Desa Nggelu yang terletak di daerah pesisir yang berbatasan dengan selat alas tidak dapat dilepaskan dari permasalahan abrasi pantai. Abrasi pantai yang merupakan proses pengikisan pantai yang dikarenakan kekuatan gelombang laut dan arus laut yang kuat dan bersifat merusak, kerusakan atau abrasi pantai disebabkan oleh gejala alami dan ulah tangan manusia. Pada dasarnya dampak yang terjadi akibat proses abrasi pantai tidak dapat dihindari, namun prosesnya saja yang lama dan ada atau tidaknya pemicu yang dapat mempercepatnya. Dampak yang ditimbulkan dari abrasi pantai diantaranya adalah kerusakan ekosistem terumbu karang, hutan mangrove secara alami, akibat pengikisan yang terjadi secara terus-menerus. Kemudian, terjadi penurunan keanekaragaman organisme disekitarnya akibat ekosistem dimana organisme tersebut lahir, tumbuh, mencari makan dan hidup, rusak dan hilangnya tempat berkumpulnya ikan ikan perairan pantai karena terkikisnya hutan bakau.

Dampak abrasi pantai lainnya juga akan sangat terlihat pada bibir pantai, dimana garis pantai akan semakin bergeser ke arah daratan, yang berarti akan terjadi penyempitan lahan tempat tinggal bagi penduduk sekitar pantai, apabila tidak diatasi lama kelamaan daerah-daerah yang permukaannya rendah akan tenggelam. Selain itu pantai yang indah dan menjadi tujuan wisata menjadi rusak. Namun abrasi pantai di Desa Nggelu sudah dapat dicegah dengan membuat tanggul di sekitar wilayah pesisir. Pembangunan tanggul di wilayah pesisir di mulai sejak bulan juni 2017. Warga pesisir Desa Nggelu sudah terlindungi dari ancaman gelombang pasang dan abrasi yang sebelumnya melanda wilayah pesisir Desa Nggelu. Hal ini seperti yang telah dipaparkan oleh salah seorang masyarakat yang tinggal di pesisir pantai Desa Nggelu, menuturkan bahwa:

2. Penanaman Mangrove

Mangrove mempunyai peranan ekologis, ekonomis, dan sosial yang sangat penting dalam mendukung pembangunan wilayah pesisir. Kerjasama pemerintah daerah, pemerintah desa dengan masyarakat wilayah pesisir pantai Desa Nggelu sudah pernah dilakukan seperti kegiatan penghijauan yang di naungi oleh Dinas Kehutanan pada tahun 2016 dengan menyediakan bibit mangrove sekitar 1000 pohon untuk ditanam di wilyah pesisir pantai Desa Nggelu. Berdasarkan hasil observasi yang dilakukan oleh peneliti, hutan mangrove yang berada di Desa Nggelu saat ini mengalami kerusakan karena kawasan mangrove beralih menjadi tambak ikan dan udang, selain itu juga di karenakan adanya eksploitasi (penebangan) tumbuhan mangrove untuk dijadikan kayu bakar oleh masyarakat disekitar pesisir.

3. Desa Nggelu menjadi daerah wisata bahari

Pengembangan desa wisata bahari/pesisir adalah sebagai salah satu produk wisata alternatif yang dapat memberikan dorongan bagi pembangunan pedesaan yang berkelanjutan serta memiliki prinsip-prinsip pengelolaan antara lain: (a) memanfaatkan potensi alam, keunikan budaya serta sarana dan prasarana masyarakat setempat; (b) Melibatkan masyarakat setempat sebagai pelaku utama kegiatan kepariwisataan; (c) Berskala kecil untuk memudahkan terjalinnya hubungan timbal balik dengan masyarakat 
setempat; (d) Menerapkan pengembangan produk wisata pedesaan yang ramah lingkungan, bercitarasa khusus serta keunikan lainnya.

Selain keuntungan secara ekonomi, hal-hal positif lainnya dalam pengembangan kawasan desa wisata bahari ini adalah terjaganya kelestarian lingkungan, terutama di kawasan pesisir serta menumbuhkan kearifan lokal dan heritage. Peresmian desa wisata bahari tersebut juga dirangkaikan dengan penanaman pohon penghijauan di sekitar pantai. Kegiatan penghijauan tersebut bagian dari program penanaman satu milyar pohon yang dicanangkan. Menimbang potensi tersebut, pemerintah Daerah propinsi Nusa Tenggara Barat berencana mengembangkan Desa Nggelu sebagai kawasan desa wisata bahari/pesisir secara terpadu dan berkesinambungan. Berbagai persiapan untuk hal tersebut telah mulai dilakukan, dari penyusunan konsep, penataan infrastruktur baik secara fisik maupun ekonomi dan penyiapan sumber daya manusianya. Diharapkan dengan pengembangan sebagai kawasan desa wisata bahari secara terpadu dan berkesinambungan ini segala potensi yang dimiliki masyarakat Desa Nggelu lebih bisa dimaksimalkan lagi baik secara ekonomis, budaya maupun peningkatan kualitas sumberdaya manusianya.

Masyarakat pesisir dalam kehidupan sehari hari tidak lepas dari ketergantungannya akan sumberdaya pesisir karena mata pencaharian penduduknya yang bergantung pada laut. Karena mata pencahariannya yang bergantung pada laut, maka masyarakat nelayan memilih untuk bertempat tinggal di wilayah pesisir. Hal ini merupakan salah satu faktor timbulnya permukiman yang berada di wilayah pesisir yang membedakannya dengan permukiman yang ada di wilayah perkabupaten. Salah faktor yang menyebabkan masyarakat bertempat tinggal di wilayah perkabupatenan adalah karena banyaknya lapangan perkerjaan yang ditawarkan. Sedangkan untuk wilayah pesisir, karena mata pencahariannya bersumber dari laut, mereka memilih untuk bertempat tinggal di wilayah pesisir.

\section{SIMPULAN DAN SARAN}

Berdasarkan hasil penelitian, maka dapat disimpulkan bahwa partisipsi masyarakat dan pemerintah dalam mengatasi bencana abrasi di Desa Nggelu Kecamatan Lambu Kabupaten Bima yaitu (1) penanaman pohon mangrove merupakan salah satu upaya Pemerintah Daerah (Pemda) di NTB khususnya yang terjadi di Desa Nggelu, dirangkaikan dengan penanaman pohon penghijauan di sekitar pantai; (2) penyuluhan hukum terhadap masyarakat Desa Nggelu, di maksudkan untuk memeberikan pengetahuan terhadap para nelayan setempat tentang peraturan perundang-undagan yang berkaitan dengan kelautan dan perikanan.

Adapun saran dalam peneliyian ini adalah (1) Kepada para masyarakat wilayah pesisir pantai Desa Nggelu agar lebih menjaga lingkungan pesisir dengan tidak membuang sampah sembarangan dan menjaga kelestarian hutan bakau (mangrove) degan tidak menebangnya; (2) Kepada pemeritah daerah Kabupaten Bima, Pemerintah Kecamatan Lambu maupun Pemerintah Desa Nggelu agar lebih menggencarkan programnya dengan cara melakukan sosialisasi secara menyeluruh kepada seluruh masyarakat pesisir dengan mengimbanginya dengan menambahkan fasilitas.

\section{REFERENSI}

Adhian, D. Suprapto, and F. Purwanti. 2014. "Persepsi Dan Partisipasi Nelayan Dalam Pengelolaan Kawasan Konservasi Laut Daerah Ujungnegoro-Roban Kabupaten Batang." Management Of Aquatic Resources 3(3): 28-33. 
Arikunto. 2010. "Suharsimi Arikunto.pdf." In Prosedur Penelitian Suatu Pendekatan PraktikRevisi Ke X,

Faisal, Mohammad, Sukuryadi Sukuryadi, and Fatma Wulandari. 2018. "A GIS-Based Analysis for Mapping the Distribution of Seaweed Cultivation Area in East Lombok Southern Coastal Waters." GeoEco 4(2): 171.

Faperi, Suyono, and Ign Boedi Hendrarto. 2015. "Management Strategies of Mangrove Degradation in Coastal Areas of Brebes Regency, Central Java, Indonesia." Journal of Coastal Zone Management 18(2).

Handayani, Gracia Dwi. 2019. "Kajian Kerentanan Bencana Tsunami Di Kawasan Pesisir." FLOBAMORA 2(1): 52-63.

Haryawan, Haryawan, and Sukuryadi Sukuryadi. 2019. "Pengelolaan Ekosistem Terumbu Karang Melalui Wisata Bahari Partisipatif Di Pantai Tiga Dusun Setangi Desa MAlaka Kecamatan Pemenang Kabupaten Lombok Utara." Jurnal Kajian Penelitian \& Pengembangan Pendidikan 7(1): 129.

Herianto, A. et al. 2020. "Analysis of Community Understanding on the Dangers of Quarry Mining to the Environment: A Case Study of Community Forest at Karang Sidemen Village North Batukliang District, Central Lombok." In IOP Conference Series: Earth and Environmental Science,

Koddeng, Baharuddin. 2011. "Zonasi Kawasan Pesisir Pantai Makassar Berbasis Mitigasi Bencana (Studi Kasus Pantai Barambong-Celebes Convention Centre).” Prosiding 2011 5(Group Teknik Arsitektur): TA17-1 - 14.

Rochayati, N. et al. 2020. "Community Understanding and Attitude Levels on the Implementation of Illegal Sand Mining on the Induk Beach, West Lombok." In IOP Conference Series: Earth and Environmental Science,.

Rochayati, Nurin, Agung Pramunarti, and Agus Herianto. 2018. "Upaya Pelestarian Potensi Pariwisata Dan Pengembangan Ekowisata Kawasan Konservasi Taman Wisata Alam Bangko-Bangko Desa Batuputih Kecamatan Sekotong Kabupaten Lombok Barat." Paedagoria | FKIP UMMat 7(1): 14

Rochayati, Nurin, Agung Pramunarti, Mas'ad Mas'ad, and Suryani Suryani. 2018. "Pemberdayaan Perempuan Pedesaan Melalui Pelatihan Pengelolaan Sampah Rumah Tangga." SELAPARANG Jurnal Pengabdian Masyarakat Berkemajuan 1(2): 9.

Sugiyono. 2013. “Buku - Sugiyono.” In Metode Penelitian Kuantitatif, Kualitatif, Dan $R$ \& D, , 407.

Sukuryadi, Nuddin Harahab, Mimit Primyastanto, and Bambang Semedi. 2020. "CollaborativeBased Mangrove Ecosystem Management Model for the Development of Marine Ecotourism in Lembar Bay, Lombok, Indonesia." Environment, Development and Sustainability.

Sukuryadi, Sukuryadi. 2018. "Pemetaan Kesesuaian Lahan Peruntukkan Daerah Pelabuhan Dengan Aplikasi Sistem Informasi Geografis Di Wilayah Pesisir Selatan Kabupaten Lombok Timur." Paedagoria | FKIP UMMat 7(2): 1.

Sukuryadi, Sukuryadi, and Ibrahim Ali. 2018. "Pemetaan Potensi Sumberdaya Wilayah Pesisir Selatan Kabupaten Lombok Timur Dengan Aplikasi Sistem Informasi Geografis." Paedagoria | FKIP UMMat 6(1): 37.

Sutrisno, Andi Irwan, and Muh Ramli. 2019. “Analisis Tingkat Kekumuhan Dan Peningkatan Permukiman Pesisir Di Desa Torokeku Kecamatan Tinanggea Kabupaten Konawe Selatan." Perencanaan Wilayah 4(1): 1-13. 